\title{
An alternative method for estimating hygroscopic growth factor of aerosol light-scattering coefficient: a case study in an urban area of Guangzhou, South China
}

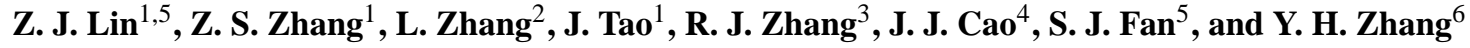 \\ ${ }^{1}$ South China Institute of Environmental Sciences, the Ministry of Environment Protection of PRC, Guangzhou, China \\ ${ }^{2}$ Air Quality Research Division, Science Technology Branch, Environment Canada, Toronto, Canada \\ ${ }^{3}$ RCE-TEA, Institute of Atmospheric Physics, Chinese Academy of Sciences, Beijing, China \\ ${ }^{4}$ Key Laboratory of Aerosol, SKLLQG, Institute of Earth Environment, Chinese Academy of Sciences, Xi' an, China \\ ${ }^{5}$ Department of Atmospheric Science, Sun Yat-Sen University, Guangzhou, China \\ ${ }^{6}$ State Joint Key Laboratory of Environmental Simulation and Pollution Control, College of Environmental Sciences and \\ Engineering, Peking University, Beijing, China
}

Correspondence to: J. Tao (taojun@scies.org)

Received: 11 December 2013 - Published in Atmos. Chem. Phys. Discuss.: 7 January 2014

Revised: 19 May 2014 - Accepted: 5 June 2014 - Published: 30 July 2014

\begin{abstract}
A method was developed to estimate hygroscopic growth factor $(\mathrm{f}(\mathrm{RH}))$ of aerosol light-scattering coefficient $\left(b_{\mathrm{sp}}\right)$, making use of the measured size- and chemically resolved aerosol samples. In this method, chemical composition of the measured aerosol samples were first reconstructed using the equilibrium model ISORROPIA II. The reconstructed chemical composition, which varies with relative humidity (RH), was then employed to calculate $b_{\mathrm{sp}}$ and hygroscopic growth factor of $b_{\mathrm{sp}}\left(f_{\mathrm{sp}}(\mathrm{RH})\right)$ using the Mie model. Furthermore, the calculated $f_{\mathrm{sp}}(\mathrm{RH})$ was fitted with an empirical curve. To evaluate the applicability of $f_{\mathrm{sp}}(\mathrm{RH})$, the curve of $f_{\mathrm{sp}}(\mathrm{RH})$ was used to correct the long-term records of the measured $b_{\mathrm{sp}}$ from the values under comparative dry conditions to the ones under ambient RH conditions. Compared with the original $b_{\mathrm{sp}}$ data, the $f_{\mathrm{sp}}(\mathrm{RH})$-corrected $b_{\mathrm{sp}}$ had a higher linear correlation with, and a smaller discrepancy from, the $b_{\mathrm{sp}}$ derived directly from visibility and absorption measurements. The $f_{\mathrm{sp}}(\mathrm{RH})$ determined here was further compared with that reported in previous studies. The method described in this manuscript provides an alternative approach to derive credible $f_{\mathrm{sp}}(\mathrm{RH})$ with high accuracy and has many potential applications in aerosol-related research.
\end{abstract}

\section{Introduction}

Atmospheric aerosols influence the radiation budget of the Atmosphere-Earth system through light scattering and absorption, which impact climate and degrade air visibility (Seinfeld and Pandis, 2006). The aerosol light-scattering coefficient $\left(b_{\mathrm{sp}}\right)$ increases with increasing relative humidity $(\mathrm{RH})$ due to the hygroscopic growth of water-soluble fractions of aerosol (Malm et al., 2003; Xu et al., 2002). Thus, higher RH may cause larger single-particle scattering albedo $\left(\omega_{0}\right)$ according to Mie theory, and as a result, a potential cooling effect on climate. Furthermore, air visibility degradation could be strengthened in areas with wet climate and high aerosol loading.

Knowledge of aerosol chemical composition is needed for calculating $b_{\text {sp }}$ under a desired RH environment using the Mie model (Seinfeld and Pandis, 2006). Accordingly, the hygroscopic growth factor of $b_{\mathrm{sp}}\left(f_{\mathrm{sp}}(\mathrm{RH})\right)$ could be determined. Thermodynamic equilibrium models such as EAIM (Wexler and Clegg, 2002) and ISORROPIA II (Fountoukis and Nenes, 2007) were thus developed for the purpose of reconstructing aerosol chemical composition, as well as estimating water content absorbed by aerosols, in various RH conditions. These models take advantage of particle size hygroscopic growth factor (Tang, 1996; Tang et al., 1997; Tang and Munkelwitz, 1994) of several pure chemical 
species established by laboratory measurements and numerical parameterization studies. On the other hand, $f_{\mathrm{sp}}(\mathrm{RH})$ can be estimated through simultaneous measurements of $b_{\mathrm{sp}}$ of both dry and ambient aerosols (the latter is in equilibrium in ambient RH conditions) using nephelometers (Malm et al., 2003; Xu et al., 2002). Recently, experiments were carried out with more advanced measurement techniques in order to determine $f_{\mathrm{sp}}(\mathrm{RH})$ of various aerosol types (Zieger et al., 2011, 2013).

In the Pearl River Delta region of South China, air visibility degradation, the so-called haze problem mainly caused by severe aerosol pollution, has attracted the attention of the public and the scientific community (Wu et al., 2005). Intensive haze episodes have sometimes occurred along with wet weather, suggesting the necessity of assessing the impact of a high-RH environment on haze formation. For this purpose, a series of field experiments were conducted to understand aerosol optical properties and the related hygroscopic behavior in the Pearl River Delta region. One of these experiments was carried out from October to November in 2004 at Xinken (Cheng et al., 2008a, b; Zhang et al., 2008b), a suburban area of Guangzhou, in which HDMPS, TDMPS, MOUDI and APS instruments were utilized to determine the particle size hygroscopic growth factor and optical refractive index under various $\mathrm{RH}$ conditions. $b_{\mathrm{sp}}$ and $f_{\mathrm{sp}}(\mathrm{RH})$ were then calculated based on the Mie model. Another experiment was performed in July 2006 within the urban area of Guangzhou to derive $b_{\mathrm{sp}}$ from visibility and absorption measurements and to compare with the nephelometer-measured ones in order to quantify $f_{\text {sp }}(\mathrm{RH})$ (Liu et al., 2008). Although these two methods are credible and have significant scientific meanings, the first one relied on a combination of complicated instruments, which is not always practical for long-term and simultaneous observations at multiple locations, whereas the second one could not be utilized to examine the effect of hygroscopic chemical species and their mixing state on the hygroscopicity of aerosol population. From 2009 to 2010, a continuous study was conducted at the observation site of the South China Institute of Environmental Sciences (SCIES) located in an urban area of Guangzhou. During this period, chemical composition of $\mathrm{PM}_{2.5}$ and particle number size distribution measured by APS were integrated into the Mie model calculation for developing a practical method to estimate $f_{\mathrm{sp}}(\mathrm{RH})$ (Lin et al., 2013). Results from the above study suggested the importance of a complete particle number size distribution for improving performance of the developed method. However, $f_{\mathrm{sp}}(\mathrm{RH})$ introduced by the studies mentioned above still need to be further evaluated with long-term measurement results.

With the aim of further development of a practical method estimating $f_{\mathrm{sp}}(\mathrm{RH})$ in mind, the size- and chemically resolved aerosol samples collected in SCIES observation site during 2010 were utilized to estimate $f_{\mathrm{sp}}(\mathrm{RH})$ in the present study. The determined $f_{\mathrm{sp}}(\mathrm{RH})$ was then applied to correct the long-term measured $b_{\mathrm{sp}}$ from the nephelometer from 2008 to 2010 . A comparison between the $f_{\mathrm{sp}}(\mathrm{RH})$-corrected $b_{\mathrm{sp}}$ and that derived from visibility and absorption measurements served as an evaluation of the determined $f_{\mathrm{sp}}(\mathrm{RH})$. In addition, the contribution of $\mathrm{RH}$ to the enhancement of $b_{\mathrm{sp}}$ and $\omega_{0}$ in the urban area of Guangzhou was separately quantified based on $f_{\mathrm{sp}}(\mathrm{RH})$.

\section{Methods}

\subsection{Experimental}

The SCIES observation site $\left(23^{\circ} 07^{\prime} \mathrm{N}, 113^{\circ} 21^{\prime} \mathrm{E}\right)$ is situated in the downtown area of Guangzhou. All instruments were installed on the roof of a building about $53 \mathrm{~m}$ above the ground. This site was built with a clear view of the surrounding area, in which there are residential buildings and a park about $500 \mathrm{~m}$ to the northeast. There is no obvious air pollution source within $3 \mathrm{~km}$ of the site except for traffic emissions. The map showing the location of SCIES and surroundings can be seen in a previous study (Lin et al., 2013). At this field site, fine-particle concentrations and aerosol optical properties, as well as gaseous pollutant concentrations and key meteorological parameters, have been recorded and studied since 2005 (Tao et al., 2009, 2012a, b, 2014) .

In this work, size-segregated aerosols were collected by a high-flow cascade impactor with particle cut-off sizes at 10 , $2.5,1.4,1.0,0.44$ and $0.25 \mu \mathrm{m}$. The impactor was operated at a flow rate of $100 \mathrm{~L} \mathrm{~min}^{-1}$ for approximately $24 \mathrm{~h}$ to collect one set of filter samples. All the samplings were performed from May to June (4, 8, 12, 16, 20, 24, 26 May; 5, 12, 18 June) and November to December (12, 14, 16, 18, 20, 22, 24, 26, 28, 30 November; 2, 4, 6, 8 December) in 2010, considering the former period as the wet season (denoted "ws") and the latter as the dry season (denoted "ds") in South China. OC (organic carbon) and EC (elemental carbon) were measured by a carbon analyzer following the NIOSH 5040 protocol. A detailed description of the measurements of $\mathrm{OC}$ and $\mathrm{EC}$ and the related bias is provided in the Supplement. Major water-soluble inorganic cations $\left(\mathrm{Na}^{+}, \mathrm{NH}_{4}^{+}, \mathrm{K}^{+}, \mathrm{Mg}^{2+}\right.$ and $\left.\mathrm{Ca}^{2+}\right)$ and anions $\left(\mathrm{SO}_{4}^{2-}, \mathrm{NO}_{3}^{-}\right.$and $\left.\mathrm{Cl}^{-}\right)$were detected by an ion chromatograph. The cations were separated on an Ionpac CS12 analytical column with a CG12 guard column using $20 \mathrm{mM}$ of methane sulfonic acid as an eluent, whereas the anions were separated on Ionpac AS14 and AG14 columns with a mixture of $4.5 \mathrm{mM}$ of $\mathrm{Na}_{2} \mathrm{CO}_{3}$ and $1.4 \mathrm{mM}$ of $\mathrm{NaHCO}_{3}$ as an eluent. More information on chemical analysis procedures mentioned above are described in another paper (Zhang et al., 2013).

The concentration of $\mathrm{BC}$ was measured using a Magee AE-31 aethalometer with a flow rate of $5 \mathrm{~L} \mathrm{~min}^{-1}$. The sampling air passed through a $\mathrm{PM}_{2.5}$ cutter and a drying tube before entering the aethalometer. The instrument was calibrated to zero by replacing the old filter in the canister inlet with a clean one every week. The concentration of $\mathrm{NO}_{2}$ was measured by a Thermo $42 \mathrm{i}$ gas analyzer. The measured $b_{\mathrm{sp}}$ 
Table 1. Summary of measurement techniques information.

\begin{tabular}{|c|c|c|c|c|c|c|}
\hline Property & Instrument & Variable & Available & $\begin{array}{l}\text { Output } \\
\text { time resolution }\end{array}$ & RH condition & $\begin{array}{l}\text { Aggregated } \\
\text { time resolution }\end{array}$ \\
\hline Particle sampling & $\begin{array}{l}\text { MSP high-flow cascade im- } \\
\text { pactor }\end{array}$ & $\begin{array}{l}\text { Particle cut-off diameter } \\
\text { and mass }\end{array}$ & $2010-05 / 06 / 11 / 12$ & $\sim 24 \mathrm{~h}$ & ambient & $\sim 24 \mathrm{~h}$ \\
\hline Chemical analysis & $\begin{array}{l}\text { Dionex ion chromatography } \\
\text { and sunset lab carbon analyzer }\end{array}$ & $\begin{array}{l}\text { Water-soluble ions and } \\
\text { OC / EC mass }\end{array}$ & $2010-05 / 06 / 11 / 12$ & $\sim 24 \mathrm{~h}$ & $\begin{array}{l}\sim 40 \% \\
\text { in laboratory }\end{array}$ & $\sim 24 \mathrm{~h}$ \\
\hline \multirow{4}{*}{ Meteorology } & \multirow{3}{*}{ VAISALA QMH102 } & Temperature & $2008-03$ to $2010-12$ & $0.5 \mathrm{~h}$ & ambient & $1 \mathrm{~h}$ and $\sim 24 \mathrm{~h}$ \\
\hline & & Relative humidity & $2008-03$ to $2010-12$ & $0.5 \mathrm{~h}$ & ambient & $1 \mathrm{~h}$ and $\sim 24 \mathrm{~h}$ \\
\hline & & Air pressure & $2008-03$ to $2010-12$ & $0.5 \mathrm{~h}$ & ambient & $1 \mathrm{~h}$ and $\sim 24 \mathrm{~h}$ \\
\hline & VAISALA PWD22 & Air visibility & $2008-03$ to $2010-12$ & $0.5 \mathrm{~h}$ & ambient & $1 \mathrm{~h}$ and $\sim 24 \mathrm{~h}$ \\
\hline Gaseous pollutant & Thermo $42 \mathrm{i}$ & Mass concentration of $\mathrm{NO}_{2}$ & $2008-03$ to $2010-12$ & $5 \mathrm{~min}$ & ambient & $1 \mathrm{~h}$ and $\sim 24 \mathrm{~h}$ \\
\hline \multirow[t]{2}{*}{$\begin{array}{l}\text { Aerosol optical } \\
\text { property }\end{array}$} & Magee AE-31 & $\begin{array}{l}\text { Mass concentration of } \\
\mathrm{BC}(880 \mathrm{~nm})\end{array}$ & $2008-03$ to $2010-12$ & $5 \mathrm{~min}$ & \multirow{2}{*}{$\begin{array}{l}\sim 40 \% \\
\text { drying tube } \\
\text { inner heating }\end{array}$} & $1 \mathrm{~h}$ and $\sim 24 \mathrm{~h}$ \\
\hline & TSI 3563 & $\begin{array}{l}\text { Scattering coefficient } \\
(550 \mathrm{~nm})\end{array}$ & $2008-03$ to $2010-04$ & $1 \mathrm{~min}$ & & $1 \mathrm{~h}$ and $\sim 24 \mathrm{~h}$ \\
\hline
\end{tabular}

was derived from a TSI 3563 Nephelometer. Calibration of the nephelometer was performed using carbon dioxide as the high-span gas and filtered air as the low-span gas. The nephelometer drew ambient air through a temperature-controlled inlet at a flow rate of $20 \mathrm{~L} \mathrm{~min}^{-1}$.

Meteorological parameters including visibility (VIS), ambient RH, air pressure (PRES) and air temperature (TEMP) were recorded every $30 \mathrm{~min}$. Visibility was observed using a VAISALA PWD22 present weather detector. Ambient RH, PRES and TEMP were measured by weather probes in VAISALA QMH102. Meteorological instruments were all mounted at $3 \mathrm{~m}$ above the platform of the observation site. Table 1 summarizes all the measurement techniques in this study.

\subsection{Reconstruction of aerosol chemical composition using ISORROPIA II model}

Taking mass concentrations of the measured water-soluble ions as input, the thermodynamic model ISORROPIA II was used to reconstruct the chemical composition of particles which were considered as supersaturated solution droplets in real atmosphere (Seinfeld and Pandis, 2006). The model was setup to solve the "Reverse" problem with the output chemical species in the "metastable" state. The recorded RH and TEMP were also input into the model. The aqueous species $\left(\mathrm{H}^{+}, \mathrm{Na}^{+}, \mathrm{NH}_{4}^{+}, \mathrm{Ca}^{2+}, \mathrm{K}^{+}, \mathrm{Mg}^{2+}, \mathrm{HSO}_{4}^{-}, \mathrm{SO}_{4}^{2-}, \mathrm{NO}_{3}^{-}\right.$and $\mathrm{Cl}^{-}$) in the model primary output were combined with each other to form chemical compounds according to the abundance of $\mathrm{SO}_{4}^{2-}$ in particles (Fountoukis and Nenes, 2007). The extent of $\mathrm{SO}_{4}^{2-}$ abundance and the related potential major compounds are described in Table 2. If any portion of $\mathrm{NO}_{3}^{-}$or $\mathrm{Cl}^{-}$remained, they were combined with $\mathrm{H}^{+}$to become $\mathrm{HNO}_{3}$ or $\mathrm{HCl}$. $\mathrm{CaSO}_{4}$ was assumed to be completely insoluble. As mentioned earlier, E-AIM is another popular tool for aerosol chemical composition reconstruction, and is what the measured water-soluble ions in this study were processed with in one instance. A comparison between the pri-
Table 2. Potential major compounds with respect to the abundance of $\mathrm{SO}_{4}^{2-}$.

\begin{tabular}{|c|c|}
\hline Abundance of $\mathrm{SO}_{4}^{2-}$ & Potential major compounds \\
\hline $\mathrm{SO}_{4}^{2-}$ rich & $\begin{array}{l}\mathrm{NaHSO}_{4}, \mathrm{NH}_{4} \mathrm{HSO}_{4}, \mathrm{KHSO}_{4} \text {, } \\
\mathrm{K}_{2} \mathrm{SO}_{4}, \quad \mathrm{MgSO}_{4}, \mathrm{Na}_{2} \mathrm{SO}_{4}, \\
\left(\mathrm{NH}_{4}\right)_{2} \mathrm{SO}_{4}, \mathrm{H}_{2} \mathrm{SO}_{4}, \mathrm{CaSO}_{4}\end{array}$ \\
\hline $\mathrm{SO}_{4}^{2-}$ less rich & $\begin{array}{lrr}\mathrm{K}_{2} \mathrm{SO}_{4}, & \mathrm{MgSO}_{4}, & \mathrm{Na}_{2} \mathrm{SO}_{4}, \\
\left(\mathrm{NH}_{4}\right)_{2} \mathrm{SO}_{4}, \quad \mathrm{H}_{2} \mathrm{SO}_{4}, & \mathrm{CaSO}_{4}, \\
\mathrm{NaNO}_{3}, & \mathrm{NaCl}, & \mathrm{NH}_{4} \mathrm{NO}_{3}, \\
\mathrm{NH}_{4} \mathrm{Cl}, & \mathrm{Ca}\left(\mathrm{NO}_{3}\right)_{2}, & \mathrm{CaCl}_{2}, \\
\mathrm{Mg}\left(\mathrm{NO}_{3}\right)_{2}, & \mathrm{MgCl}_{2}, \mathrm{KNO}_{3}, \mathrm{KCl}\end{array}$ \\
\hline $\mathrm{SO}_{4}^{2-}$ poor & $\begin{array}{l}\mathrm{NaNO}_{3}, \quad \mathrm{NaCl}, \quad \mathrm{NH}_{4} \mathrm{NO}_{3}, \\
\mathrm{NH}_{4} \mathrm{Cl}, \quad \mathrm{Ca}\left(\mathrm{NO}_{3}\right)_{2}, \quad \mathrm{CaCl}_{2}, \\
\mathrm{Mg}\left(\mathrm{NO}_{3}\right)_{2}, \mathrm{MgCl}_{2}, \mathrm{KNO}_{3}, \mathrm{KCl}\end{array}$ \\
\hline
\end{tabular}

mary output of ISORROPIA II and E-AIM is presented in the Supplement.

The mass concentration of POM (particulate organic matter) was estimated to be 1.6 times that of $\mathrm{OC}$ for urban aerosols (Cao et al., 2007; Turpin and Lim, 2001; Xing et al., 2013). Unlike water-soluble components, the water absorbed by POM was not considered here due to the lack of (1) adequate data for the speciation of WSOC in POM and (2) the accurate RH dependence curve for WSOC. EC was also not assumed to undergo hygroscopic growth.

\subsection{Calculation of $b_{\text {sp }}$ using the Mie model}

The reconstructed chemical composition in Sect. 2.2 was then used to calculate $b_{\mathrm{sp}}$ on the basis of Mie theory. Optical properties of aerosol population can be calculated with particle number concentration and the scattering/absorption efficiency of a single particle (Bohren and Huffman, 1998). Three different assumptions of particle mixing state (Bond 
Table 3. Density and optical refractive index of each chemical component.

\begin{tabular}{|c|c|c|c|c|c|c|c|}
\hline \multirow{2}{*}{ Species } & \multirow{2}{*}{$\rho$} & \multicolumn{2}{|c|}{$m(=n+k i)$} & \multirow{2}{*}{ Species } & \multirow{2}{*}{$\rho$} & \multicolumn{2}{|c|}{$m(=n+k i)$} \\
\hline & & $n$ & $k$ & & & $n$ & $k$ \\
\hline $\mathrm{NH}_{4} \mathrm{HSO}_{4}$ & 1.780 & 1.473 & 0.000 & $\mathrm{KHSO}_{4}$ & 2.245 & 1.480 & 0.000 \\
\hline$\left(\mathrm{NH}_{4}\right)_{2} \mathrm{SO}_{4}$ & 1.760 & 1.530 & 0.000 & $\mathrm{Ca}\left(\mathrm{NO}_{3}\right)_{2}$ & 2.504 & 1.530 & 0.000 \\
\hline $\mathrm{NaHSO}_{4}$ & 2.476 & 1.460 & 0.000 & $\mathrm{CaCl}_{2}$ & 2.150 & 1.520 & 0.000 \\
\hline $\mathrm{Na}_{2} \mathrm{SO}_{4}$ & 2.680 & 1.480 & 0.000 & $\mathrm{Mg}\left(\mathrm{NO}_{3}\right)_{2}$ & 2.020 & 1.510 & 0.000 \\
\hline $\mathrm{NH}_{4} \mathrm{NO}_{3}$ & 1.725 & 1.554 & 0.000 & $\mathrm{MgCl}_{2}$ & 2.325 & 1.540 & 0.000 \\
\hline $\mathrm{NaNO}_{3}$ & 2.261 & 1.587 & 0.000 & $\mathrm{KNO}_{3}$ & 2.110 & 1.504 & 0.000 \\
\hline $\mathrm{NH}_{4} \mathrm{Cl}$ & 1.527 & 1.639 & 0.000 & $\mathrm{KCl}$ & 1.980 & 1.490 & 0.000 \\
\hline $\mathrm{NaCl}$ & 2.160 & 1.544 & 0.000 & $\mathrm{HNO}_{3}^{*}$ & 1.504 & 1.396 & 0.000 \\
\hline $\mathrm{K}_{2} \mathrm{SO}_{4}$ & 2.660 & 1.490 & 0.000 & $\mathrm{HCl}^{*}$ & 1.198 & 1.342 & 0.000 \\
\hline $\mathrm{MgSO}_{4}$ & 2.660 & 1.560 & 0.000 & $\mathrm{H}_{2} \mathrm{O}$ & 1.000 & 1.333 & 0.000 \\
\hline $\mathrm{CaSO}_{4}$ & 2.610 & 1.570 & 0.000 & POM & 1.400 & 1.550 & 0.001 \\
\hline $\mathrm{H}_{2} \mathrm{SO}_{4}$ & 1.840 & 1.430 & 0.000 & $\mathrm{EC}$ & 1.500 & 1.800 & 0.540 \\
\hline
\end{tabular}

* Updated in this study.

and Bergstrom, 2005; Seinfeld and Pandis, 2006) are concerned here, which are "internally mixed" (volume averaged), "externally mixed" and "core-shell mixed" (encapsulated) (denoted below by subscripts int, ext and cs, respectively). The formulas for the Mie model calculations with these mixing states assumptions are described by Eqs. (1), (2) and (3), respectively, where the subscripts $i$ and $j$ denote the $i$ th chemical component and the $j$ th stage of particle size, respectively.

$b_{\mathrm{sp} / \mathrm{ap}, \text { int, cal }}=$

$\sum_{j} \frac{\pi D_{j}^{2}}{4} \cdot Q_{\mathrm{sp} / \mathrm{ap}, \text { int }}\left(\lambda, D_{j}, \sum_{i} \alpha_{i, j} m_{i, j}\right) \cdot N_{j}$

$b_{\text {sp } / \text { ap,ext,cal }}=$

$\sum_{j} \sum_{i} \frac{\pi D_{i, j}^{2}}{4} \cdot Q_{\mathrm{sp} / \mathrm{ap}, \text { ext }, i, j}\left(\lambda, D_{i, j}, m_{i, j}\right) \cdot N_{i, j}$

$b_{\mathrm{sp} / \mathrm{ap}, \mathrm{cs}, \mathrm{cal}}=\sum_{j} \frac{\pi D_{j}^{2}}{4}$.

$Q_{\mathrm{sp} / \mathrm{ap}, \mathrm{cs}}\left(\lambda, D_{j, c}, D_{j, s}, m_{j, c}, \sum_{i} \alpha_{i, j, s} m_{i, j, s}\right) \cdot N_{j}$

$Q_{\text {sp/ap }}$ is the single-particle scattering/absorption efficiency, the calculations of which can be found in the study by Bohren and Huffman (1998). $\lambda$ represents the light wavelength and refers to $550 \mathrm{~nm}$ throughout this work. $D$ is the particle volumetric equivalent diameter and was calculated based on the median cut-off aerodynamic diameter $\left(D_{\mathrm{a}}\right)$ of the employed cascade impactor and the particle density $(\rho)$ (see Eq. (4) below). $N$ stands for the particle number concentration and was calculated using Eq. (5). $C$ in Eqs. (5) and (6) refers to the mass concentration of reconstructed chemical component. $\alpha$ stands for the component's volume fraction and was calculated using Eq. (6). $m(=n+k i)$ is the particle optical refractive index (ORI). Values of $\rho$ and $m$ are stated in a previous study by Lin et al. (2013) and are also listed here in Table 3. Computational codes of the calculations mentioned above were integrated into MATLAB scripts for batch processing.

$$
\begin{aligned}
& D=D_{\mathrm{a}} \cdot \frac{1}{\sqrt{\rho}} \\
& N=\frac{6 \cdot C}{\pi \cdot D^{3} \cdot \rho} \\
& \alpha_{i, j}=\frac{C_{i, j}}{\rho_{i}} / \sum_{i} \frac{C_{i, j}}{\rho_{i, j}}
\end{aligned}
$$

\subsection{Estimation and parameterization of $f_{\mathrm{sp}}(\mathbf{R H})$}

The water-soluble fractions of aerosol, such as ammonia sulfate and sodium chloride, absorb more water in environments with higher RH. Thus, aerosol chemical composition varies with $\mathrm{RH}$, and the density and ORI of aerosol particles changes as a result. The RH input into ISORROPIA II can be tuned in a desired range, and then chemical composition at a certain RH can be determined by the model. This illustrates a way to simulate RH dependence of $b_{\mathrm{sp}}$ based on the Mie model making use of ISORROPIA II.

$f_{\mathrm{sp}}(\mathrm{RH})$ is the ratio of $b_{\mathrm{sp}}(\mathrm{RH})$ to $b_{\mathrm{sp}}\left(\mathrm{RH}_{0}\right)$, where $\mathrm{RH}_{0}$ refers to an RH condition under which particles are considered to be too dry to grow. It should be noted that particle number concentration in each particle size range was assumed to be unchanged through hygroscopic growth. Equation (4) had to be modified for calculating $b_{\mathrm{sp}}(\mathrm{RH})$. As $D$ in Eq. (4) was determined under ambient RH conditions, hygroscopic growth of particle size, $D(\mathrm{RH})$, should be considered when RH conditions change. Therefore, hygroscopic growth factor of particle size, $g(\mathrm{RH})$, which is the ratio of $D(\mathrm{RH})$ to 
$D\left(\mathrm{RH}_{0}\right)$, was included in Eq. (4) to form Eq. (7).

$D(\mathrm{RH})=D_{\mathrm{a}}\left(\mathrm{RH}_{\mathrm{amb}}\right) \cdot \frac{1}{\sqrt{\rho\left(\mathrm{RH}_{\mathrm{amb}}\right)}} \cdot \frac{g(\mathrm{RH})}{g\left(\mathrm{RH}_{\mathrm{amb}}\right)}$

$g(\mathrm{RH})$ in Eq. (7) can be calculated using Eq. (8) from a previous study (Lin et al., 2013).

$g(\mathrm{RH})=\left(\frac{V_{\text {water }}(\mathrm{RH})+V_{\text {dry_particle }}}{V_{\text {dry_particle }}}\right)^{1 / 3}$

$V_{\text {water }}$ of both internally mixed particles and core-shell mixed particles are referred to the total volume of water absorbed by particles. $V_{\text {water }}$ under this circumstance can be determined based on the total amount of water predicted by ISORROPIA II. However, with regard to externally mixed particles, $V_{\text {water }}$ cannot be determined from ISORROPIA II because the amount of water separately absorbed by each hygroscopic chemical component was not recorded in model output due to the model design. To overcome this problem, an assumption was made in light of a previous paper (Cheng et al., 2008a): an externally mixed particle is considered to be composed of three groups of components. To form one of the three groups, inorganic salts and water mixed with each other following the volume-average rule; POM and EC formed the other two groups. These three groups were externally mixed with each other. This three-group mixing state was denoted "semi-externally mixed" for simple description below. Accordingly, the water amount predicted by ISORROPIA II can still be utilized to quantify $\mathrm{V}_{\text {water }}$ of the group mixed with inorganic salts and water.

For the convenience of future applications, $f_{\mathrm{sp}}(\mathrm{RH})$ was usually parameterized empirically, and the following function was found to be the best curve fitting:

$f_{\mathrm{sp}}(\mathrm{RH})=\left(\frac{1-\mathrm{RH}}{1-\mathrm{RH}_{0}}\right)^{-a \cdot(\mathrm{RH}+b)}$.

RH within a range of 0.12 to 0.96 was recorded at our site from 2008 to 2010. Furthermore, ISORROPIA II was run under the metastable state, which allows particles to absorb water at low- $\mathrm{RH}$ conditions. Therefore, $\mathrm{RH}_{0}$ in Eq. (9) was initially set to 0.10 , and then the values of $f_{\mathrm{sp}}(\mathrm{RH})$ at $\mathrm{RH}$ in the range of 0.10 to 0.96 were determined.

\subsection{Evaluation of $f_{\mathrm{sp}}(\mathrm{RH})$}

Particles drawn into the nephelometer were heated for the purpose of RH control. $b_{\mathrm{sp}}$ measured by the nephelometer was corrected by $f_{\mathrm{sp}}(\mathrm{RH})$ to its value in the ambient environment where particles underwent hygroscopic growth. Eq. (10) describes such correction, where $b_{\mathrm{sp} \text {,cal stands for }}$ the $f_{\mathrm{sp}}(\mathrm{RH})$-corrected $b_{\mathrm{sp}}$.

$b_{\mathrm{sp}, \mathrm{cal}}\left(\mathrm{RH}_{\mathrm{amb}}\right)=b_{\mathrm{sp}}\left(\mathrm{RH}_{\mathrm{nep}}\right) \cdot \frac{f_{\mathrm{sp}}\left(\mathrm{RH}_{\mathrm{amb}}\right)}{f_{\mathrm{sp}}\left(\mathrm{RH}_{\mathrm{nep}}\right)}$
Before the correction using Eq. (10), the nephelometermeasured $b_{\mathrm{sp}}$ was first corrected for angular nonidealities following the method presented in the study by Anderson and Ogren (1998).

Also, $b_{\text {sp }}$ can be estimated by Eq. (11) based on visibility and absorption measurements (Seinfeld and Pandis, 2006) and is denoted $b_{\mathrm{sp}, \text { mea }}$ below:

$b_{\mathrm{sp}, \text { mea }}=b_{\text {ext,mea }}-b_{\text {ap,mea }}-b_{\mathrm{ag}, \text { mea }}-b_{\mathrm{sg}, \text { mea }}$.

In Eq. (11), $b_{\text {ext,mea }}$ represents the total light extinction coefficient and was derived from visibility following Eq. (12), which is stated in the users' manual of PWD22. $b_{\mathrm{ag} \text {,mea }}$ stands for light absorption by gaseous pollutants and was estimated practically by mass concentration of $\mathrm{NO}_{2}$ following Eq. (13) (Pitchford et al., 2007). $\mathrm{C}_{\mathrm{NO}_{2}}$ and $\mathrm{M}_{\mathrm{NO}_{2}}$ in Eq. (13) are mass concentration and molecular weight of $\mathrm{NO}_{2}$, respectively.

$b_{\text {ext,mea }}=\frac{3}{\text { visibility }}$

$b_{\text {ag, mea }}=330 \cdot 22.4 \cdot \frac{C_{\mathrm{NO}_{2}}}{M_{\mathrm{NO}_{2}}}$

Light scattering by air, denoted $b_{\text {sg,mea }}$, was calculated using Eq. (14) (Seinfeld and Pandis, 2006). The mass concentration of $\mathrm{BC}, \mathrm{C}_{\mathrm{bc}, 880 \mathrm{~nm}}$, was used to estimate $b_{\mathrm{ap}}$ at a light wavelength of $532 \mathrm{~nm}$ following a linear relationship described in Eq. (15) (Wu et al., 2009). The $532 / 550$ added to Eq. (15) is to correct $b_{\text {ap,mea }}$ from its value at $532 \mathrm{~nm}$ to that at $550 \mathrm{~nm}$ (Bergstrom et al., 2002).

$b_{\mathrm{sg}, \text { mea }}=11.4 \cdot \frac{293}{\mathrm{TEMP}} \cdot$ PRES
$b_{\mathrm{ap}, \text { mea }}=\left(8.28 \cdot C_{\mathrm{bc}, 880 \mathrm{~nm}}+2.23\right) \cdot(532 / 550)$

Finally, the correlation between $b_{\mathrm{sp}, \mathrm{cal}}$ and $b_{\mathrm{sp} \text {,mea }}$ was examined using linear regression, which was considered as an evaluation of the determined $f_{\mathrm{sp}}(\mathrm{RH})$. A summary of the fundamental data involved in this evaluation is shown statistically in Table 4.

\section{Results and discussion}

\subsection{Reconstructed aerosol chemical composition}

Measured inorganic ions were needed as model input for ISORROPIA II to reconstruct aerosol chemical composition. The ions, as well as OC and EC, were collected from May to June and November to December in 2010. First, the data were briefly examined to ensure data quality (Fig. 1). The charge equivalence of cations was highly correlated to that of anions in each particle size range (Fig. 1a), and a slope of 1.00 was found in the linear regression, indicating the balance of charge equivalence among the ions. This balance warranted the proper functioning of ISORROPIA II and 
Table 4. Statistical results of fundamental data in the evaluation of $f_{\mathrm{sp}}(\mathrm{RH})$.

\begin{tabular}{llccc}
\hline Variable & Unit & $\begin{array}{c}\text { May-Jun 2010 } \\
(\sim 24 \mathrm{~h} \text { average })\end{array}$ & $\begin{array}{c}\text { Nov-Dec 2010 } \\
(\sim 24 \mathrm{~h} \text { average })\end{array}$ & $\begin{array}{c}\text { Mar 2008-Dec 2010 } \\
(1 \mathrm{~h} \text { average })\end{array}$ \\
\hline$b_{\text {sp,mea }}$ & $\mathrm{Mm}^{-1}$ & $526.3 \pm 290.5$ & $479.0 \pm 197.9$ & $529.1 \pm 490.4$ \\
$b_{\text {sp,cal }}^{*}$ & $\mathrm{Mm}^{-1}$ & - & - & $350.3 \pm 277.1$ \\
$\mathrm{RH}_{\text {vis }}$ & & $0.71 \pm 0.09$ & $0.48 \pm 0.09$ & $0.66 \pm 0.17$ \\
$\mathrm{RH}_{\text {nep }}$ & & - & - & $0.52 \pm 0.13$ \\
$b_{\text {ag,mea }}$ & $\mathrm{Mm}^{-1}$ & $12.4 \pm 5.5$ & $11.9 \pm 3.6$ & $11.0 \pm 6.0$ \\
$b_{\text {sg,mea }}$ & $\mathrm{Mm}^{-1}$ & $11.1 \pm 0.1$ & $11.4 \pm 0.1$ & $11.3 \pm 0.3$ \\
$b_{\text {ap,mea }}$ & $\mathrm{Mm}^{-1}$ & $42.1 \pm 25.5$ & $46.4 \pm 17.4$ & $59.0 \pm 42.2$ \\
$\mathrm{Na}^{+}$ & $\mu \mathrm{g} \mathrm{m}^{-3}$ & $2.20 \pm 1.86$ & $0.91 \pm 0.47$ & - \\
$\mathrm{SO}_{4}^{2-}$ & $\mu \mathrm{g} \mathrm{m}^{-3}$ & $13.53 \pm 5.74$ & $16.60 \pm 5.11$ & - \\
$\mathrm{NH}_{4}^{+}$ & $\mu \mathrm{g} \mathrm{m}^{-3}$ & $5.36 \pm 3.15$ & $6.84 \pm 2.33$ & - \\
$\mathrm{NO}_{3}^{-}$ & $\mu \mathrm{g} \mathrm{m}^{-3}$ & $9.02 \pm 5.36$ & $9.67 \pm 5.81$ & - \\
$\mathrm{Cl}^{-}$ & $\mu \mathrm{g} \mathrm{m}^{-3}$ & $1.72 \pm 0.64$ & $1.03 \pm 1.02$ & - \\
$\mathrm{Ca}^{2+}$ & $\mu \mathrm{g} \mathrm{m}^{-3}$ & $1.56 \pm 0.56$ & $1.63 \pm 0.57$ & - \\
$\mathrm{K}^{+}$ & $\mu \mathrm{g} \mathrm{m}^{-3}$ & $0.57 \pm 0.32$ & $1.32 \pm 0.39$ & - \\
$\mathrm{Mg}^{2+}$ & $\mu \mathrm{g} \mathrm{m}^{-3}$ & $0.23 \pm 0.08$ & $0.17 \pm 0.06$ & - \\
$\mathrm{OC}^{2}$ & $\mu \mathrm{g} \mathrm{m}^{-3}$ & $9.46 \pm 3.66$ & $14.30 \pm 4.38$ & - \\
$\mathrm{EC}^{2}$ & $\mu \mathrm{g} \mathrm{m}^{-3}$ & $4.02 \pm 3.81$ & $4.53 \pm 2.56$ & \\
\hline
\end{tabular}

* Without the $f_{\mathrm{sp}}(\mathrm{RH})$ correction.
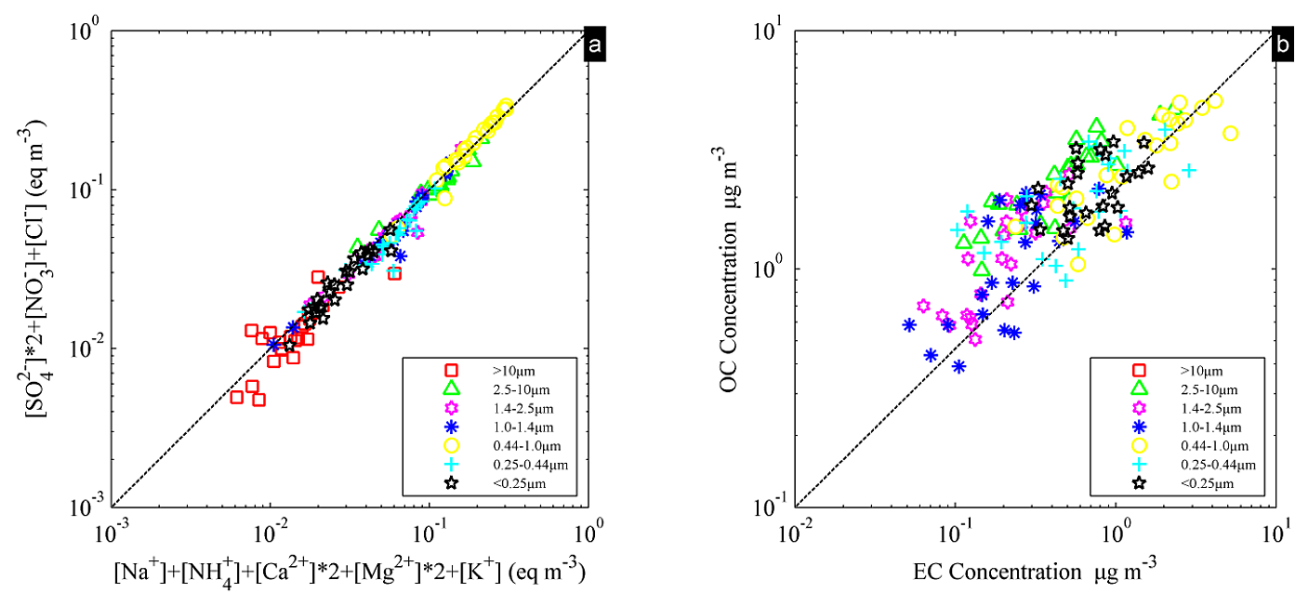

Figure 1. Measurement data collected during May, June, November and December in 2010. (a) The balance of charge equivalence between cations and anions. (b) Mass concentrations of EC versus OC.

high accuracy of the modeling results $(95 \pm 5 \%$ according to mass conservation of chemical species between the model input and output data). The mass concentration of ions peaked in the size ranges of $0.44-1 \mu \mathrm{m}$ and $2.5-10 \mu \mathrm{m}$, which can be explained by the different dominant ions in different size ranges (e.g., Zhang et al., 2008a). The correlation between the mass of OC and EC is shown in Fig. 1b. Note that mass concentrations of $\mathrm{OC}$ and $\mathrm{EC}$ in the size range of $>10 \mu \mathrm{m}$ were not weighed in the laboratory and thus are not shown in Fig. 1b. EC and OC had significant linear correlations in size ranges of $0.44-1 \mu \mathrm{m}$ and $2.5-10 \mu \mathrm{m}$, with $\mathrm{R}^{2}$ being 0.58 and 0.73 , respectively.
The reconstructed aerosol chemical composition was briefly discussed below. It should be noted that the total mass of each aerosol sample mentioned throughout this paper is the sum of all the determined chemical components. The unidentified components were initially assumed to be negligible in mass and light-scattering effect compared to the determined ones.

Figures 2 and 3 present the reconstructed aerosol chemical composition. The major chemical compounds in aerosols were $\left(\mathrm{NH}_{4}\right)_{2} \mathrm{SO}_{4}, \mathrm{Na}_{2} \mathrm{SO}_{4}, \mathrm{NH}_{4} \mathrm{NO}_{3}, \mathrm{NaNO}_{3}, \mathrm{~K}_{2} \mathrm{SO}_{4}$, $\mathrm{CaSO}_{4}, \mathrm{Ca}\left(\mathrm{NO}_{3}\right)_{2}, \mathrm{H}_{2} \mathrm{O}, \mathrm{POM}$ and EC. As illustrated in Fig. 2, they accounted for most of the total mass. Specifically, 
Table 5. Statistics of $f_{\mathrm{sp}}(\mathrm{RH})$ curve fitting by Eq. (9) with constant parameter "b".

\begin{tabular}{|c|c|c|c|c|c|c|c|c|c|c|c|c|}
\hline \multirow[t]{2}{*}{ "b" } & \multicolumn{4}{|c|}{$f_{\mathrm{sp}, \text { int }}$} & \multicolumn{4}{|c|}{$f_{\text {sp,ext }}$} & \multicolumn{4}{|c|}{$f_{\mathrm{sp}, \mathrm{cs}}$} \\
\hline & average "a" & $\begin{array}{c}\text { Standard } \\
\text { deviation "a" }\end{array}$ & $\begin{array}{l}\text { average } \\
\text { residual }\end{array}$ & $\begin{array}{l}\text { average } \\
\text { correlation } \\
\text { coefficient }\end{array}$ & average "a" & $\begin{array}{c}\text { Standard } \\
\text { deviation "a" }\end{array}$ & $\begin{array}{l}\text { average } \\
\text { residual }\end{array}$ & $\begin{array}{c}\text { average } \\
\text { correlation } \\
\text { coefficient }\end{array}$ & average "a" & $\begin{array}{c}\text { Standard } \\
\text { deviation "a" }\end{array}$ & $\begin{array}{l}\text { average } \\
\text { residual }\end{array}$ & $\begin{array}{c}\text { average } \\
\text { correlation } \\
\text { coefficient }\end{array}$ \\
\hline-0.10 & 0.6038 & 0.0230 & 0.6319 & 0.9880 & 0.5719 & 0.0242 & 0.6124 & 0.9858 & 0.6110 & 0.0239 & 0.6462 & 0.9881 \\
\hline-0.05 & 0.5690 & 0.0205 & 0.5770 & 0.9890 & 0.5388 & 0.0216 & 0.5560 & 0.9871 & 0.5757 & 0.0213 & 0.6138 & 0.9886 \\
\hline 0.00 & 0.5379 & 0.0184 & 0.5401 & 0.9896 & 0.5093 & 0.0193 & 0.5159 & 0.9879 & 0.5443 & 0.0191 & 0.5974 & 0.9888 \\
\hline 0.05 & 0.5100 & 0.0166 & 0.5167 & 0.9900 & 0.4829 & 0.0174 & 0.4883 & 0.9885 & 0.5160 & 0.0172 & 0.5930 & 0.9888 \\
\hline 0.10 & 0.4848 & 0.0150 & 0.5037 & 0.9902 & 0.4590 & 0.0158 & 0.4703 & 0.9888 & 0.4905 & 0.0156 & 0.5973 & 0.9887 \\
\hline 0.15 & 0.4620 & 0.0137 & 0.4985 & 0.9902 & 0.4374 & 0.0144 & 0.4595 & 0.9890 & 0.4674 & 0.0142 & 0.6082 & 0.9885 \\
\hline 0.20 & 0.4412 & 0.0125 & 0.4993 & 0.9901 & 0.4177 & 0.0132 & 0.4545 & 0.9890 & 0.4464 & 0.0130 & 0.6239 & 0.9882 \\
\hline 0.25 & 0.4222 & 0.0115 & 0.5048 & 0.9900 & 0.3996 & 0.0121 & 0.4539 & 0.9890 & 0.4271 & 0.0119 & 0.6432 & 0.9878 \\
\hline 0.30 & 0.4048 & 0.0106 & 0.5137 & 0.9898 & 0.3831 & 0.0111 & 0.4566 & 0.9889 & 0.4095 & 0.0110 & 0.6650 & 0.9873 \\
\hline 0.35 & 0.3887 & 0.0098 & 0.5253 & 0.9895 & 0.3678 & 0.0103 & 0.4620 & 0.9887 & 0.3932 & 0.0101 & 0.6886 & 0.9869 \\
\hline 0.40 & 0.3738 & 0.0091 & 0.5390 & 0.9892 & 0.3538 & 0.0095 & 0.4695 & 0.9885 & 0.3782 & 0.0094 & 0.7134 & 0.9864 \\
\hline
\end{tabular}
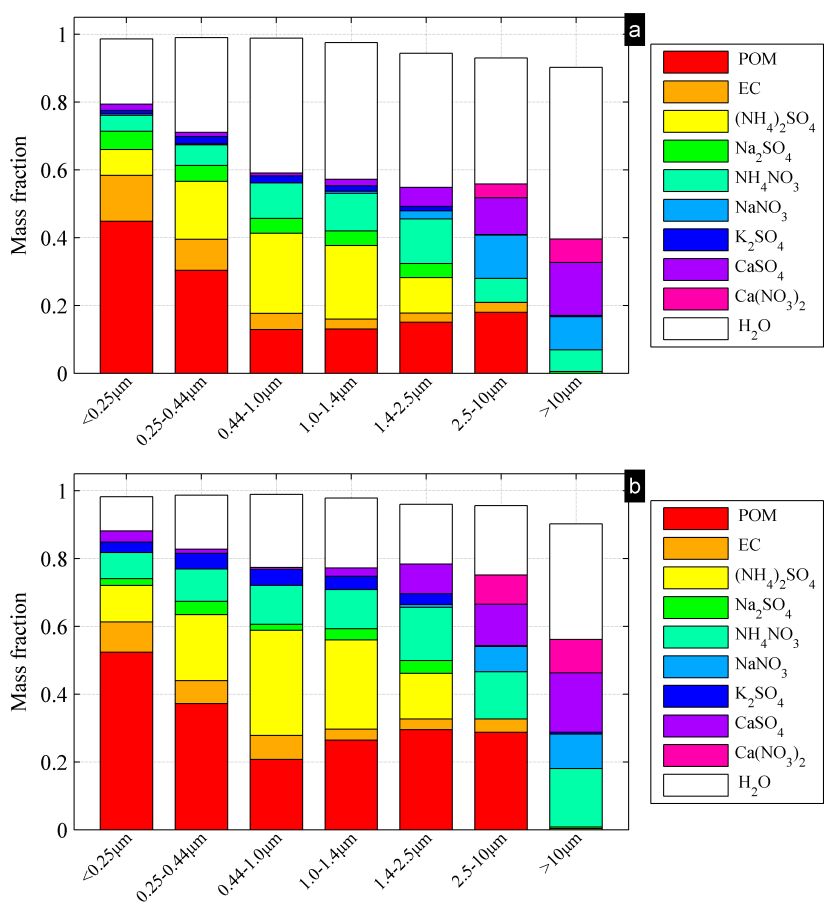

Figure 2. Mass fractions of the reconstructed major chemical constituents in different particle size ranges in the wet (a) and dry (b) season.

major inorganic salts accounted for about $35-55 \%$ of the total mass in particles larger than $0.44 \mu \mathrm{m}$, and less in smaller particles. In contrast, POM and EC contributed about 40$60 \%$ in particles smaller than $0.44 \mu \mathrm{m}$ and about $15-35 \%$ in larger particles. Generally, calcium salts and $\mathrm{NaNO}_{3}$ were mostly in coarse particles, whereas ammonia salts, $\mathrm{Na}_{2} \mathrm{SO}_{4}$ and $\mathrm{K}_{2} \mathrm{SO}_{4}$ were in fine ones.

The mass fraction of each major compound differed between the wet and dry season, with a distinct difference in water content. The mass fraction of $\mathrm{K}_{2} \mathrm{SO}_{4}$ significantly increased in the dry season compared to that in the wet season, whereas that of sodium salts decreased. Although the mass fraction of each major compound varied with season, the size distribution pattern of each major compound was similar between the two seasons (Fig. 3). Specifically, $\left(\mathrm{NH}_{4}\right)_{2} \mathrm{SO}_{4}$, $\mathrm{Na}_{2} \mathrm{SO}_{4}$ and $\mathrm{K}_{2} \mathrm{SO}_{4}$ peaked in the size range of 0.44-1.0 $\mu \mathrm{m}$; $\mathrm{NaNO}_{3}, \mathrm{CaSO}_{4}$ and $\mathrm{Ca}\left(\mathrm{NO}_{3}\right)_{2}$ in 2.5-1.0 $\mu \mathrm{m}$; and $\mathrm{NH}_{4} \mathrm{NO}_{3}$, $\mathrm{H}_{2} \mathrm{O}$, POM and EC had two peaks, one of $0.44-1.0 \mu \mathrm{m}$ and another of $2.5-1.0 \mu \mathrm{m}$.

\section{2 $b_{\text {sp }}$ of the mixed aerosol}

ORI of aerosol particles is one of the key parameters for calculating $b_{\text {sp }}$, and can be determined by the volume ratios of the reconstructed chemical constituents for mixed particles. ORI of internally mixed particles represents the integrated property of the particle population. Following the volumeaverage rule,the calculated ORI of internally mixed particles tended to exhibit the ORI of the chemical component which has the largest volume fraction in particles. As illustrated in Fig. $4 \mathrm{a}$ and $\mathrm{b}$, due to smaller water fractions (Fig. 3), the real part of ORI of particles in each size range generally increased in the dry season when compared to that in the wet season. Larger EC fractions in smaller particles accounted for a larger imaginary part of ORI. This phenomenon was more obvious in the wet season than in the dry season.

$b_{\text {sp }}$ was calculated after inputting all the required parameters into the Mie model. For validation, the modeled $b_{\mathrm{sp}}$ was compared with $b_{\text {sp }}$ derived from visibility and absorption measurements. These two data sets covered the same time periods from May to June and November to December in 2010. Regardless of particle mixing state, the modeled $b_{\mathrm{sp}}$ had strong linear correlations with the measured $b_{\mathrm{sp}}$, with $\mathrm{R}^{2}$ reaching around 0.85 (Fig. $4 \mathrm{c}$ ). However, the regression slopes deviated from 1.00 and the model calculation only matched around $45 \%$ of the measured magnitude. The potential cause for this discrepancy could be a truncation error in the model calculation, as the range of each size bin of the employed impactor was too wide to obtain a highresolution particle number size distribution. Not considering the contributions of the unidentified chemical constituents 

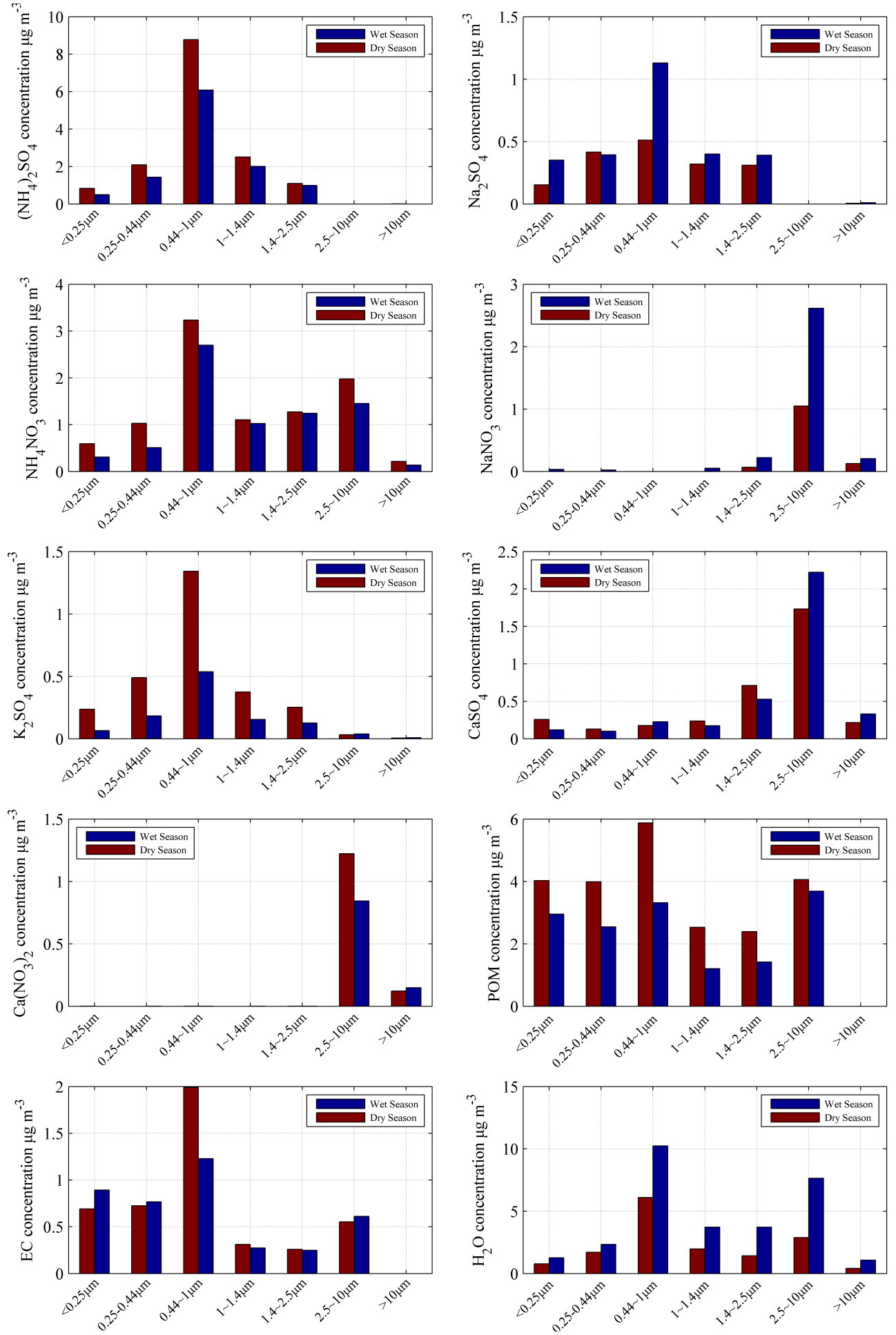

Figure 3. Mass size distributions of the reconstructed major chemical constituents.

to $b_{\text {sp }}$ in the calculation could be another potential cause to some extent.

At the same time, $b_{\text {ap }}$ calculated using the Mie model was validated with $b_{\text {ap }}$ derived from the aethalometer (Fig. 4d).
Figure $4 d$ indicates that the modeled $b_{\text {ap }}$ was also highly correlated to the measured one in spite of the particle mixing state. On the other hand, the modeled magnitude of $b_{\text {ap }}$ largely depended on particle mixing state, which was 104 , 

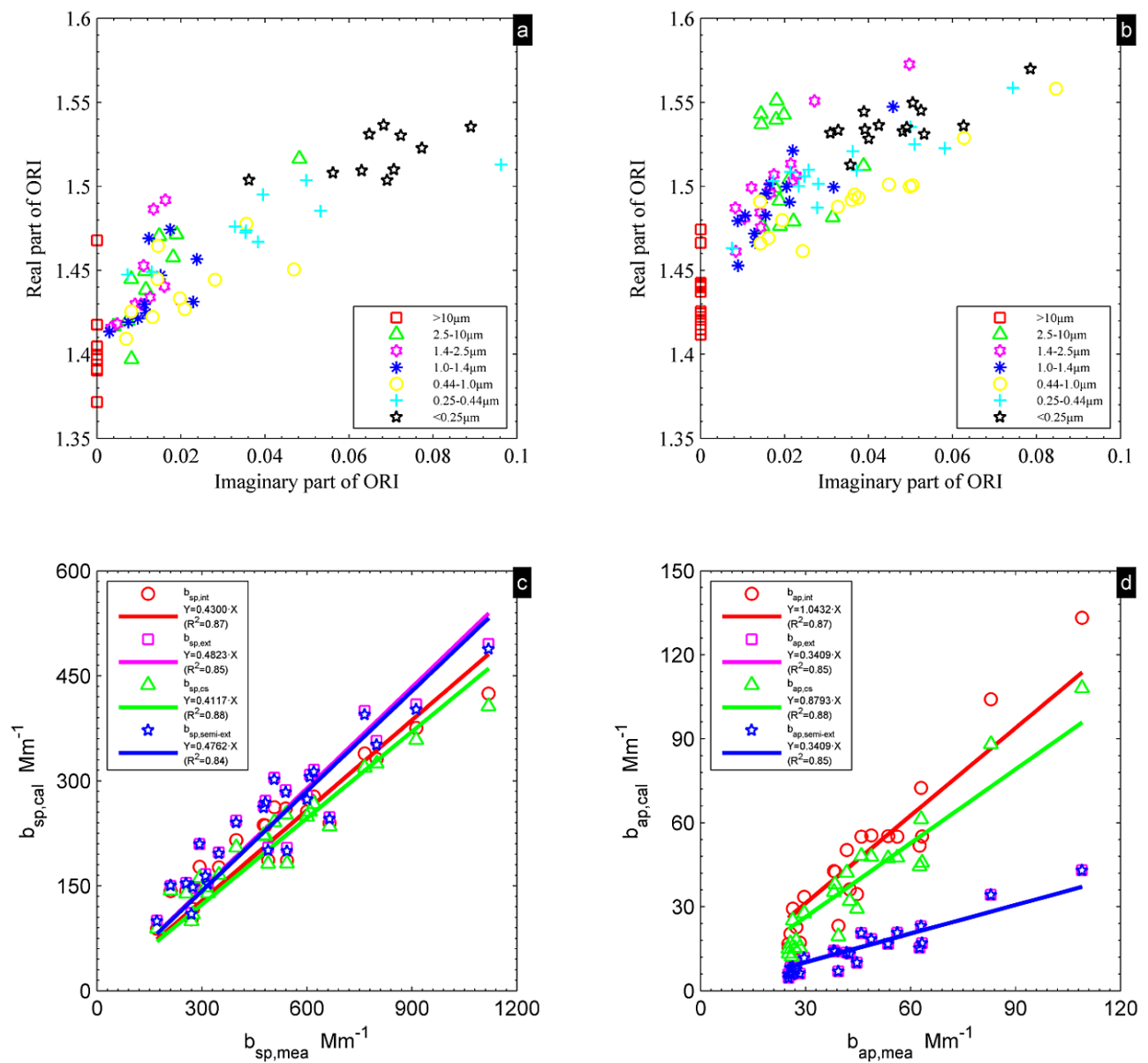

Figure 4. The imaginary part versus the real part of the optical refractive index in the wet (a) and dry (b) season, Mie-model-calculated $b_{\mathrm{sp}}$ of mixed particles versus visibility-derived $b_{\mathrm{sp}}$ (c), and Mie-model-calculated $b_{\text {ap }}$ of mixed particles versus aethalometer-derived $b_{\text {ap }}(\mathbf{d})$.

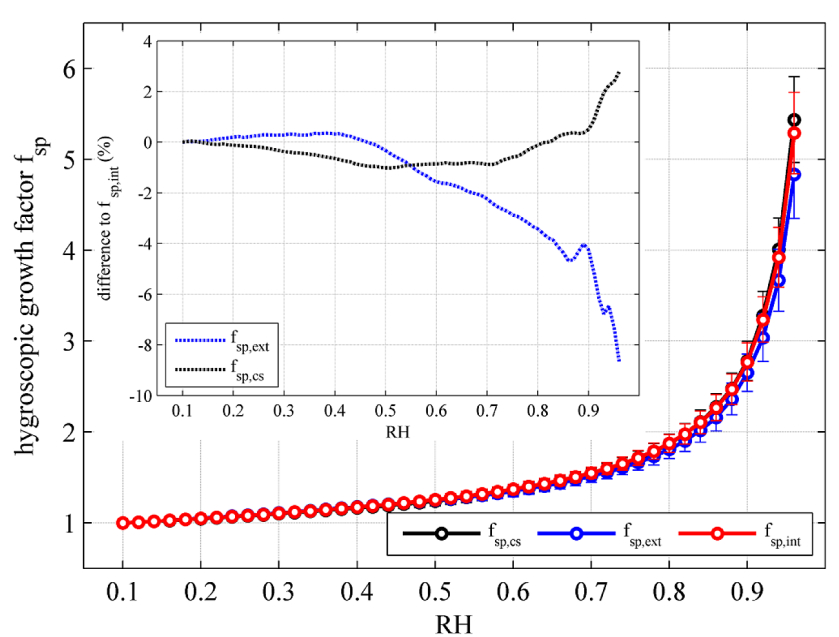

Figure 5. $f_{\mathrm{sp}}(\mathrm{RH})$ for the three types of mixed particles and the related difference. The bars stand for one standard deviation.
34 and $88 \%$ of the measured magnitude for $b_{\text {ap,int }}, b_{\text {ap,ext }}$ and $b_{\text {ap,cs }}$, respectively. This result implies that the portions of particles in different mixing states could be estimated.

\subsection{Parameterization of $f_{\mathrm{sp}}(\mathrm{RH})$}

The model-calculated $b_{\mathrm{sp}}$ in the present study can be utilized to derive $f_{\mathrm{sp}}(\mathrm{RH})\left(=b_{\mathrm{sp}}(\mathrm{RH}) / b_{\mathrm{sp}}\left(\mathrm{RH}_{0}\right)\right)$ considering the existence of strong linear correlations between the modeled and the measured $b_{\mathrm{sp}}$. In addition, $b_{\mathrm{sp}}\left(\mathrm{RH}_{0}\right)$ and $b_{\mathrm{sp}}(\mathrm{RH})$ should both be subjected to the same type of truncation error, which would eventually minimize the impact of the truncation error on their ratio $f_{\mathrm{sp}}(\mathrm{RH})$.

It is found that the model-calculated $b_{\text {sp }}$ for externally mixed was very close to that for semi-externally mixed (Fig. $4 \mathrm{c}$ and d). Thus, $b_{\mathrm{sp}}$ for semi-externally mixed was used to determine $f_{\mathrm{sp}}(\mathrm{RH})$ in the following discussions in order to take advantage of the total water amount predicted by ISORROPIA II. Accordingly, the subscript "ext" below is referred to semi-externally mixed. 
Table 6. Comparison between $f_{\mathrm{sp}}(\mathrm{RH})$ obtained in this study and those reported in previous studies.

\begin{tabular}{|c|c|c|c|c|c|c|c|c|c|c|}
\hline \multirow{3}{*}{ Study } & \multirow{2}{*}{\multicolumn{2}{|c|}{$\begin{array}{c}\text { National Park } \\
\text { Malm et al. (2003) }\end{array}$}} & \multirow{2}{*}{\multicolumn{2}{|c|}{$\begin{array}{c}\text { Urban } \\
\text { Liu et al. (2008) }\end{array}$}} & \multirow{2}{*}{\multicolumn{2}{|c|}{$\begin{array}{c}\text { Urban }\left(f_{\mathrm{sp}, \text { int }}\right) \\
\text { This study }\end{array}$}} & \multirow{2}{*}{\multicolumn{2}{|c|}{$\begin{array}{l}\text { Urban }\left(f_{\text {sp,int }}\right) \\
\text { Lin et al. }(2013)\end{array}$}} & \multirow{2}{*}{\multicolumn{2}{|c|}{$\begin{array}{c}\text { Suburban }\left(f_{\text {sp,int }}\right) \\
\text { Cheng et al. }(2008 \mathrm{a})\end{array}$}} \\
\hline & & & & & & & & & & \\
\hline & Mean & SD & Mean $^{\mathrm{a}, \mathrm{c}}$ & SD & Mean ${ }^{b, c}$ & $\mathrm{SD}^{\mathrm{b}, \mathrm{c}}$ & Mean ${ }^{b, c}$ & $\mathrm{SD}^{\mathrm{b}, \mathrm{c}}$ & Mean $^{a}$ & $\mathrm{SD}^{\mathrm{a}}$ \\
\hline \multicolumn{11}{|l|}{$\mathrm{RH}$} \\
\hline $30-35$ & 1.02 & 0.13 & 1.01 & - & 1.01 & 0.01 & 1.00 & 0.00 & 1.00 & 0.00 \\
\hline $35-40$ & 1.07 & 0.07 & 1.04 & - & 1.05 & 0.01 & 1.08 & 0.06 & 1.01 & 0.00 \\
\hline $40-45$ & 1.11 & 0.07 & 1.07 & - & 1.08 & 0.02 & 1.13 & 0.05 & 1.02 & 0.00 \\
\hline $45-50$ & 1.15 & 0.08 & 1.12 & - & 1.12 & 0.02 & 1.19 & 0.06 & 1.04 & 0.00 \\
\hline $50-55$ & 1.21 & 0.07 & 1.18 & - & 1.16 & 0.03 & 1.23 & 0.06 & 1.07 & 0.01 \\
\hline $55-60$ & 1.28 & 0.09 & 1.26 & - & 1.22 & 0.03 & 1.28 & 0.08 & 1.12 & 0.01 \\
\hline $60-65$ & 1.38 & 0.12 & 1.35 & - & 1.28 & 0.04 & 1.35 & 0.07 & 1.17 & 0.02 \\
\hline $65-70$ & 1.48 & 0.16 & 1.48 & - & 1.36 & 0.04 & 1.42 & 0.09 & 1.25 & 0.03 \\
\hline $70-75$ & 1.67 & 0.19 & 1.62 & - & 1.47 & 0.06 & 1.50 & 0.10 & 1.37 & 0.04 \\
\hline $75-80$ & 1.76 & 0.14 & 1.80 & - & 1.62 & 0.08 & 1.61 & 0.13 & 1.53 & 0.07 \\
\hline $80-85$ & 2.06 & 0.25 & 2.00 & - & 1.85 & 0.12 & 1.77 & 0.16 & 1.77 & 0.10 \\
\hline $85-90$ & 2.64 & 0.43 & 2.24 & - & 2.25 & 0.20 & 2.06 & 0.25 & 2.19 & 0.17 \\
\hline
\end{tabular}

${ }^{a}$ Calculated based on the parameterized $f_{\mathrm{sp}}(\mathrm{RH})$ curve.

b Calculated based on the $f_{\mathrm{sp}}(\mathrm{RH})$ without parameterization.

${ }^{c} f_{\mathrm{sp}}(\mathrm{RH})=b_{\mathrm{sp}}(\mathrm{RH}) / b_{\mathrm{sp}}\left(\mathrm{RH}_{0}=0.3\right)$ in order to be properly compared with the results from other studies.

Figure 5 plots the average $f_{\text {sp }}(\mathrm{RH})$ (referred to $\left.\mathrm{RH}_{0}=0.1\right)$ generated from all 24 aerosol samples and the related standard deviations. $f_{\mathrm{sp}}(\mathrm{RH})$ for the three different mixing states were all similar, as the differences were in the range of -5 to $1 \%$ at $\mathrm{RH}$ between 0.1 and $0.9 . f_{\mathrm{sp}}(\mathrm{RH})$ generally increased with increasing $\mathrm{RH}$, and reached around 2.77 at $\mathrm{RH}$ of 0.9 . The standard deviation of $f_{\mathrm{sp}}(\mathrm{RH})$ increased to nearly $8 \%$ of the average $f_{\mathrm{sp}}(\mathrm{RH})$ value at $\mathrm{RH}$ of 0.9 . It can be inferred that the seasonal variations in particle chemical composition, as well as the changes of particle mixing state, only had a small impact on $f_{\mathrm{sp}}(\mathrm{RH})$ under most $\mathrm{RH}$ conditions.

A two-parameter function, such as Eq. (9), could be more suitable for practical application if one of the two parameters is set to be a constant. Since parameter $a$ in Eq. (9) controls the rate of hygroscopic growth, tuning parameter $b$ is reasonable and comprehensive. Ranging parameter $b$ from -0.1 to 0.4 with increment of 0.05 , the average of $a$, the standard deviation of $a$, the average residual of curve fitting and the average correlation coefficient of curve fitting by Eq. (9) among all samples were examined (Table 5). The best fitting using Eq. (9) can be achieved by setting parameter $b$ to $0.15,0.25$ and 0.05 with regard to $f_{\mathrm{sp}, \text { int }}, f_{\mathrm{sp} \text {,ext }}$ and $f_{\mathrm{sp}, \mathrm{cs}}$, respectively, since the standard deviation of $a$, as well as the average residual of curve fitting, reached the valley point while the average correlation coefficient of curve fitting stayed at a high level. In comparison, setting parameter $b$ to zero for all the three mixing states can also have a comparatively low standard deviation of $a$ and a low average residual while maintaining a high average correlation coefficient. Therefore, for simplicity, parameter $b$ was set to zero in Eq. (9) for all the mixing states, and the corresponding parameter $a$ was 0.5379 ,
0.5093 and 0.5443 for $f_{\mathrm{sp}, \text { int }}, f_{\mathrm{sp}, \mathrm{ext}}$ and $f_{\mathrm{sp}, \mathrm{cs}}$, respectively. Under this circumstance, the variation of parameter $a$ had correlations with the mass fraction of water-soluble inorganic salts in dry particles, with the correlation coefficient being $0.74,0.86$ and 0.62 for $f_{\mathrm{sp}, \text { int }}, f_{\mathrm{sp}, \text { ext }}$ and $f_{\mathrm{sp}, \mathrm{cs}}$, respectively. This implies that the larger the portion of the water-soluble inorganic salts is, the higher the hygroscopic growth rate of $b_{\text {sp }}$ will be.

\subsection{Evaluation and application of $f_{\mathrm{sp}}(\mathrm{RH})$}

To evaluate the $f_{\mathrm{sp}}(\mathrm{RH})$ curve developed above, the nephelometer-measured $b_{\mathrm{sp}}$ was corrected with $f_{\mathrm{sp}}(\mathrm{RH})(\mathrm{re}-$ ferred to as $\left.b_{\text {sp,cal }}\right)$ and then compared with $b_{\text {sp }}$ derived directly from visibility and absorption measurements (referred to as $b_{\text {sp,mea }}$. As an example, $f_{\text {sp,int }}$ was used and the comparison results are presented in Fig. 6. The data sets involved in the comparison covered the period of March 2008 to April 2010 and were grouped based on the month of the year in order to show any possible seasonality. During this period, the monthly average ambient RH was in the range of 0.56-0.78, higher than that inside the nephelometer, which was in the range of $0.43-0.63$ (Fig. 6a). Figure $6 \mathrm{~b}$ illustrates the number of validated data (NVD) in the comparison.

A linear regression with zero intercept was used to correlate $b_{\mathrm{sp}, \mathrm{cal}}$ and $b_{\mathrm{sp} \text {,mea }}$. Before applying $f_{\mathrm{sp}}(\mathrm{RH})$ correction to the nephelometer-measured $b_{\mathrm{sp}}$, the correlation between $b_{\text {sp,cal }}$ and $b_{\text {sp,mea }}$ had a $\mathrm{R}^{2}$ around 0.70 and a slope ranging between 0.45 and 0.84 . With $f_{\mathrm{sp}}(\mathrm{RH})$ correction, $R^{2}$ was in a narrow range of 0.83-0.94 whereas the slope was in the range of 0.66-0.99. Note that the slopes in August, September, 


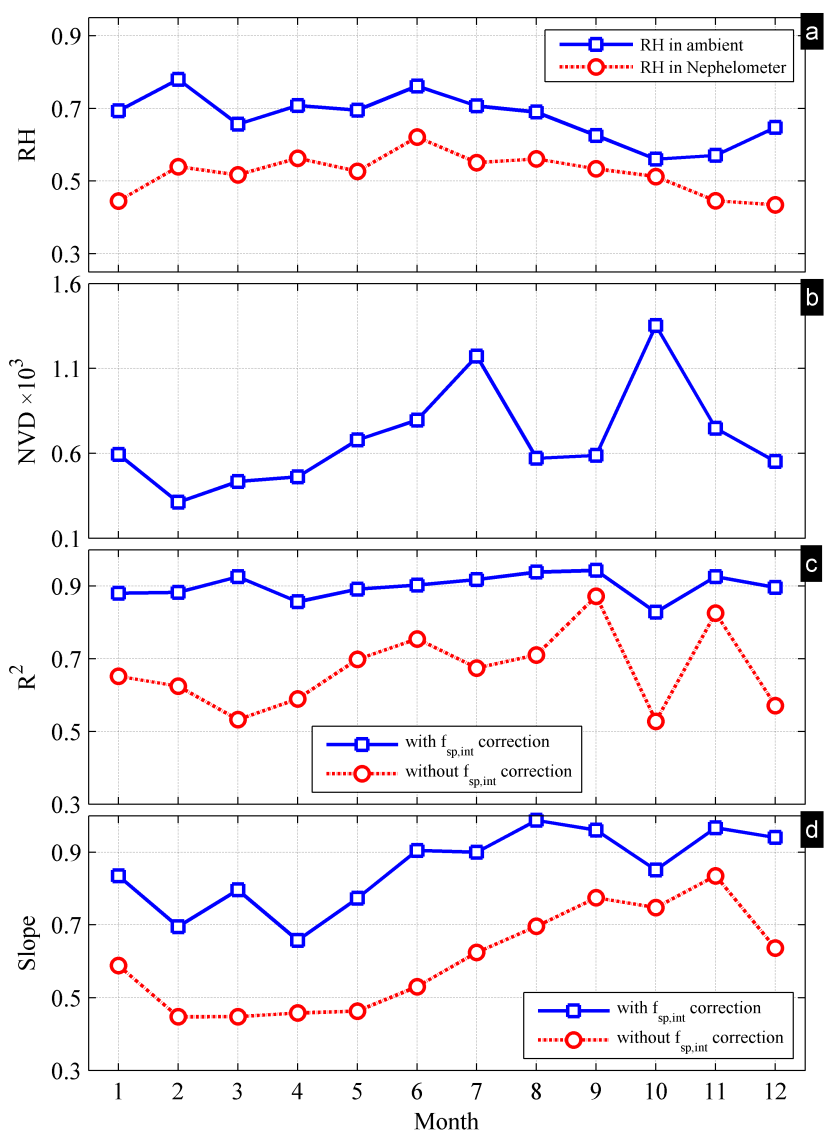

Figure 6. (a) Comparison of $\mathrm{RH}$ between ambient and inside the nephelometer, the number of data samples (b), $R^{2}$ (c) and slope (d) of the linear regression between the nephelometer-measured $b_{\mathrm{sp}}$ and visibility-derived $b_{\mathrm{sp}}$.

November and December approached 1.00. Applying $f_{\text {sp,ext }}$ or $f_{\mathrm{sp}, \mathrm{cs}}$ into the corresponding $b_{\mathrm{sp}}$ correction showed similar results to using $f_{\mathrm{sp} \text {,int }}$. Clearly, the $f_{\mathrm{sp}}(\mathrm{RH})$ correction remarkably improved the correlation and the agreement between $b_{\mathrm{sp}, \mathrm{cal}}$ and $b_{\mathrm{sp}, \mathrm{mea}}$.

It is worth mentioning that our observation site is located in a region with a wet climate. Each aerosol sample inside the nephelometer was heated in order to keep the instrument functioning properly. As mentioned in Sect. 3.1, aerosols absorb more water during the wet season, and thus the heating drove off water and probably lowered $b_{\mathrm{sp}}$ irreversibly. Moreover, this study only considered the hygroscopic growth of water-soluble fractions in inorganic salts and did not include the hygroscopicity of water-soluble fractions in POM. However, water-soluble fractions in POM could significantly grow with RH higher than about 0.6 (Gysel et al., 2004). These two causes could play a large role in the discrepancies between $b_{\mathrm{sp}, \mathrm{cal}}$ and $b_{\mathrm{sp} \text {,mea }}$ during February and April, despite including $f_{\mathrm{sp}}(\mathrm{RH})$ correction at that time.

For further evaluation, $f_{\mathrm{sp}}(\mathrm{RH})$ in this study was compared with that reported in previous studies (Table 6). Note that

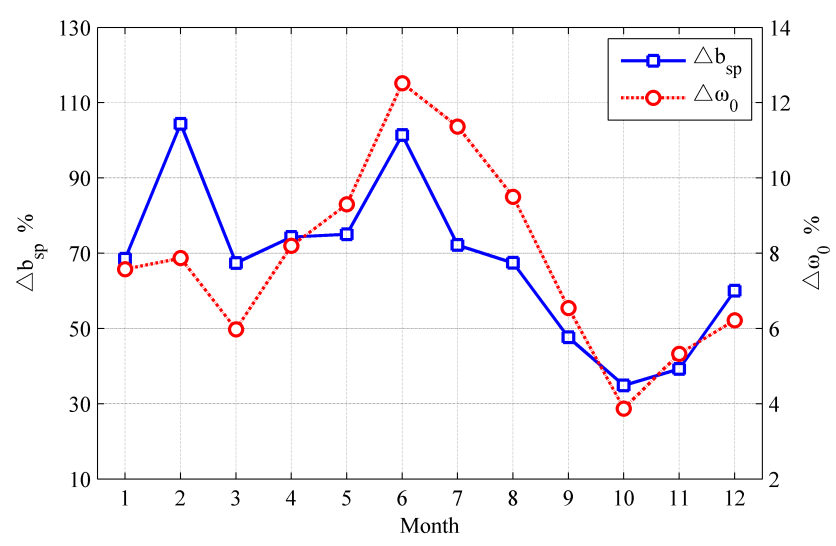

Figure 7. Contribution of RH to $b_{\mathrm{sp}}$ and $\omega_{0}$ enhancement.

the values of $f_{\mathrm{sp}}(\mathrm{RH})$ in Table 6 were all calculated based on the ratio of $b_{\mathrm{sp}}(\mathrm{RH})$ to $b_{\mathrm{sp}}\left(\mathrm{RH}_{0}=0.3\right)$ in order to have proper comparisons among results from various studies. $\mathrm{RH}$ dependence of $f_{\mathrm{sp}}(\mathrm{RH})$ obtained in this work was consistent with that from other studies, though some small differences existed. Specifically, (1) when compared with the direct measurement results (Liu et al., 2008; Malm et al., 2003), $f_{\mathrm{sp}}(\mathrm{RH})$ determined here was slightly underestimated, and the underestimation generally greater as $\mathrm{RH}$ increased; (2) when compared with the result from a numerical study also without considering the hygroscopicity of water-soluble organic fractions (Cheng et al., 2008a), $f_{\mathrm{sp}}(\mathrm{RH})$ determined here had only a slight overestimation; (3) when compared to the result from another numerical study (Lin et al., 2013), $f_{\mathrm{sp}}(\mathrm{RH})$ in this study was slightly underestimated at $\mathrm{RH}$ between 0.30 and 0.76 and overestimated at higher RH. Given the fact stated in point 2 , it is speculated that including hygroscopic growth of water-soluble organic fractions and the potential hygroscopicity of the unidentified chemical component in the $f_{\mathrm{sp}}(\mathrm{RH})$ calculation will minimize the underestimation discussed in point 1 . Regarding point 3 above, when compared with the results from this study, the previous study might have underestimated the mass fractions of watersoluble species in particles of certain size ranges as particles' chemical compositions were uniformized in all particles' size ranges there.

Overall, the method described in this paper employed simple measurements and modeling procedures to derive credible $f_{\mathrm{sp}}(\mathrm{RH})$ with high accuracy, which is particularly suitable for long-term and simultaneous field studies at multiple locations. Furthermore, the enhancement of $b_{\mathrm{sp}}$ and $\omega_{0}$ by RH from 2008 to 2010 in the urban area of Guangzhou can be quantified with $f_{\mathrm{sp}}(\mathrm{RH})$. The enhancement of $b_{\mathrm{sp}}, \Delta b_{\mathrm{sp}}$, is defined as the ratio of $\left(b_{\mathrm{sp}}\left(\mathrm{RH}_{\mathrm{amb}}\right)-b_{\mathrm{sp}}(\mathrm{RH}=0.1)\right) / b_{\mathrm{sp}}(\mathrm{RH}=0.1)$, while the enhancement of $\omega_{0}, \Delta \omega_{0}$, is calculated as $\left(\omega_{0}\left(\mathrm{RH}_{\mathrm{amb}}\right)\right.$ $\left.\omega_{0}(\mathrm{RH}=0.1)\right) / \omega_{0}(\mathrm{RH}=0.1)$. Note that $\omega_{0}$ was derived from the nephelometer and aethalometer measurement results, and 
Table 7. The uncertainties attributed to input parameters of $f_{\mathrm{sp}}(\mathrm{RH})$ calculation.

\begin{tabular}{lc}
\hline Parameter & Uncertainty (\%) \\
\hline Particle volumetric equivalent diameter & $5.00^{\mathrm{a}}$ \\
Mass of water-soluble ions and OC / EC & $3.75^{\mathrm{b}}$ \\
Ambient TEMP & $2.40^{\mathrm{c}}$ \\
Ambient RH & $3.04^{\mathrm{c}}$ \\
Real part of ORI of EC & $3.00^{\mathrm{d}}$ \\
Imaginary part of ORI of EC & $5.00^{\mathrm{d}}$ \\
\hline
\end{tabular}

${ }^{a}$ Estimated based on the stability of flow rate, ${ }^{b}$ estimated based on the detection limit, ${ }^{c}$ taken from technical sheet of the weather probe, and ${ }^{\mathrm{d}}$ taken from a previous study (Cheng et al. 2008a).

the hygroscopicity of absorption effect was not considered here. As illustrated in Fig. 7, $b_{\mathrm{sp}}$ had two peaks respectively in February and June, and a valley point in October. Under ambient RH conditions, $b_{\text {sp }}$ was strengthened by $67-104 \%$ from January to August and by 35-60\% from September to December. At the same time, the enhancement of $\omega_{0}$ ranged around 6-9\% from January to May, peaked at around $12 \%$ from June to July, and then dropped to nearly $4 \%$ in October before bouncing back to about $6 \%$ in November and December.

\subsection{Uncertainties}

Potential sources of uncertainties in this study include direct measurements, laboratory analysis and parameters chosen in model calculations. Table 7 lists the uncertainties attributed to input parameters of $f_{\mathrm{sp}}(\mathrm{RH})$ calculation. Accordingly, the overall uncertainty of calculated $f_{\mathrm{sp}}(\mathrm{RH})$ was estimated to be $9.38 \%$ using Eq. (16), where $\mathrm{U}_{i}$ refers to the uncertainty of the $i$ th parameter:

$U_{\text {total }}=\left(\sum_{i} U_{i}^{2}\right)^{1 / 2}$.

\section{Summary and conclusion}

By making use of size- and chemically resolved aerosol samples, the aerosol chemical composition under a desired $\mathrm{RH}$ condition was reconstructed using ISORROPIA II model. The major chemical constituents were $\left(\mathrm{NH}_{4}\right)_{2} \mathrm{SO}_{4}, \mathrm{Na}_{2} \mathrm{SO}_{4}$, $\mathrm{NH}_{4} \mathrm{NO}_{3}, \mathrm{NaNO}_{3}, \mathrm{~K}_{2} \mathrm{SO}_{4}, \mathrm{CaSO}_{4}, \mathrm{Ca}\left(\mathrm{NO}_{3}\right)_{2}, \mathrm{H}_{2} \mathrm{O}, \mathrm{POM}$ and EC. The mass fractions of $\mathrm{H}_{2} \mathrm{O}$ and $\mathrm{K}_{2} \mathrm{SO}_{4}$ obviously differed between the wet and dry season. Although the mass concentrations of the major constituents varied with season, their mass size distribution showed similar patterns between the two seasons. Calcium salts and $\mathrm{NaNO}_{3}$ were mostly in coarse particles, while ammonia salts, $\mathrm{Na}_{2} \mathrm{SO}_{4}$ and $\mathrm{K}_{2} \mathrm{SO}_{4}$ were in fine ones. Aerosol optical properties were calculated using the Mie model based on the reconstructed aerosol chemical composition. The modeled $b_{\text {sp }}$ correlated well with the measured $b_{\mathrm{sp}}$. The model magnitude of $b_{\mathrm{sp}}$ was smaller than the measured one by a factor of 2 , which was probably caused by the truncation error delivered from the lowresolution measured particle number size distribution.

$f_{\mathrm{sp}}(\mathrm{RH})$, the hygroscopic growth factor of $b_{\mathrm{sp}}$, can still be determined on the basis of the modeled $b_{\mathrm{sp}}$ under desired RH conditions, considering not only the strong linear correlations between the calculated and the measured $b_{\text {sp }}$ but also the minimum impact of the truncation error in the calculated $b_{\mathrm{sp}}$ on $f_{\mathrm{sp}}(\mathrm{RH})$. After fitting by an empirical curve, $f_{\mathrm{sp}}(\mathrm{RH})$ was applied to correct nephelometermeasured $b_{\mathrm{sp}}$. With $f_{\mathrm{sp}}(\mathrm{RH})$ correction, the linear correlation between nephelometer-measured $b_{\mathrm{sp}}$ and visibility-derived $b_{\text {sp }}$ was significantly improved to a higher level, and the discrepancy between these two data sets was reduced substantially. This result served as an evaluation of the determined $f_{\mathrm{sp}}(\mathrm{RH})$. A good agreement between $f_{\mathrm{sp}}(\mathrm{RH})$ values developed here and those reported in previous studies further suggests that the method described in this paper is capable of deriving credible $f_{\mathrm{sp}}(\mathrm{RH})$ with high accuracy by merely employing simple measurements and modeling techniques. As an example of $f_{\mathrm{sp}}(\mathrm{RH})$ application, the enhancements of $b_{\mathrm{sp}}$ and $\omega_{0}$ in ambient RH conditions were assessed for the urban area of Guangzhou. One lesson learned from this study is that the RH-controlled procedure inside the nephelometer should be carefully used in future experiments since the heating could lower $b_{\mathrm{sp}}$ of the aerosol sample irreversibly. Moreover, the contribution of hygroscopic growth of water-soluble organic fractions to $f_{\mathrm{sp}}(\mathrm{RH})$ needs further investigation.

\section{The Supplement related to this article is available online at doi:10.5194/acp-14-7631-2014-supplement.}

Acknowledgements. This study was supported by Environment Protection Commonweal Section (201409009), and the National Basic Research Program of China (2013FY112700).

Edited by: S. C. Liu

\section{References}

Anderson, T. L. and Ogren, J. A.: Determining Aerosol Radiative Properties Using the TSI 3563 Integrating Nephelometer, Aerosol Science and Technology, 29, 57-69, doi:10.1080/02786829808965551, 1998.

Bergstrom, R. W., Russell, P. B., and Hignett, P.: Wavelength Dependence of the Absorption of Black Carbon Particles: Predictions and Results from the TARFOX Experiment and Implications for the Aerosol Single Scattering Albedo, J. Atmos. Sci., 59, 567-577, doi:10.1175/1520-0469(2002), 2002.

Bohren, C. F. and Huffman, D. R.: Absorption and Scattering of Light by Small Particles, John Wiley \& Sons, Inc., New York, 1998. 
Bond, T. C. and Bergstrom, R. W.: Light absorption by carbonaceous particles: an investigative review, Aerosol Sci. Technol., $39,1-41,2005$.

Cao, J. J., Lee, S. C., Chow, J. C., Watson, J. G., Ho, K. F., Zhang, R. J., Jin, Z. D., Shen, Z. X., Chen, G. C., Kang, Y. M., Zou, S. C., Zhang, L. Z., Qi, S. H., Dai, M. H., Cheng, Y., and Hu, K.: Spatial and seasonal distributions of carbonaceous aerosols over China, Journal of Geophysical Research, 112, D22S11, doi:10.1029/2006JD008205, 2007.

Cheng, Y. F., Wiedensohler, A., Eichler, H., Heintzenberg, J., Tesche, M., Ansmann, A., Wendisch, M., Su, H., Althausen, D., Herrmann, H., Gnauk, T., Brüggemann, E., Hu, M. and Zhang, Y. H.: Relative humidity dependence of aerosol optical properties and direct radiative forcing in the surface boundary layer at Xinken in Pearl River Delta of China: An observation based numerical study, Atmos. Environ., 42, 6373-6397, 2008a.

Cheng, Y. F., Wiedensohler, A., Eichler, H., Su, H., Gnauk, T., Brüggemann, E., Herrmann, H., Heintzenberg, J., Slanina, J., Tuch, T., Hu, M. and Zhang, Y. H.: Aerosol optical properties and related chemical apportionment at Xinken in Pearl River Delta of China, Atmos. Environ., 42, 6351-6372, 2008b.

Fountoukis, C. and Nenes, A.: ISORROPIA II: a computationally efficient thermodynamic equilibrium model for $\mathrm{K}^{+}-\mathrm{Ca}^{2+}$ $\mathrm{Mg}^{2+}-\mathrm{NH}_{4}^{+}-\mathrm{Na}^{+}-\mathrm{SO}_{4}^{2-}-\mathrm{NO}_{3}^{-}-\mathrm{Cl}^{-}-\mathrm{H}_{2} \mathrm{O}$ aerosols, Atmos. Chem. Phys., 7, 4639-4659, doi:10.5194/acp-7-4639-2007, 2007.

Gysel, M., Weingartner, E., Nyeki, S., Paulsen, D., Baltensperger, U., Galambos, I. and Kiss, G.: Hygroscopic properties of watersoluble matter and humic-like organics in atmospheric fine aerosol, Atmos. Chem. Phys., 4, 35-50, doi:10.5194/acp-4-352004, 2004.

Lin, Z. J., Tao, J., Chai, F. H., Fan, S. J., Yue, J. H., Zhu, L. H., Ho, K. F. and Zhang, R. J.: Impact of relative humidity and particles number size distribution on aerosol light extinction in the urban area of Guangzhou, Atmos. Chem. Phys., 13, 1115-1128, doi:10.5194/acp-13-1115-2013, 2013.

Liu, X. G., Cheng, Y. F., Zhang, Y. H., Jung, J. S., Sugimoto, N., Chang, S., Kim, Y. J., Fan, S. J., and Zeng, L. M.: Influences of relative humidity and particle chemical composition on aerosol scattering properties during the 2006 PRD campaign, Atmospheric Environment, 42, 1525-1536, 2008.

Malm, W. C., Day, D. E., Kreidenweis, S. M., Collett, J. L., and Lee, T.: Humidity-dependent optical properties of fine particles during the Big Bend Regional Aerosol and Visibility Observational Study, J. Geophys. Res. Atmos., 108, 4279, doi:10.1029/2002JD002998, 2003.

Pitchford, M., Maim, W., Schichtel, B., Kumar, N., Lowenthal, D., and Hand, J.: Revised algorithm for estimating light extinction from IMPROVE particle speciation data, J. Air Waste Manag. Assoc., 57, 1326-1336, 2007.

Seinfeld, J. H. and Pandis, S. N.: Atmospheric Chemistry and Physics: from air pollution to climate change (Second Edition), John Wiley \& Sons Inc., New York, 2006.

Tang, I. N.: Chemical and size effects of hygroscopic aerosols on light scattering coefficients, Journal of Geophysical Research, 101, 19245-19250, doi:10.1029/96JD03003, 1996.

Tang, I. N. and Munkelwitz, H. R.: Water activities, densities, and refractive indices of aqueous sulfates and sodium nitrate droplets of atmospheric importance, J. Geophys. Res., 99, 18801-18808, doi:10.1029/94JD01345, 1994.

Tang, I. N., Tridico, A. C. and Fung, K. H.: Thermodynamic and optical properties of sea salt aerosols, J. Geophys. Res., 102, 2326923275, doi:10.1029/97JD01806, 1997.

Tao, J., Cao, J., Zhang, R., Zhu, L., Zhang, T., Shi, S. and Chan, C.: Reconstructed light extinction coefficients using chemical compositions of $\mathrm{PM}_{2.5}$ in winter in Urban Guangzhou, China, Advances in Atmospheric Sciences, 29, 359-368, doi:10.1007/s00376-011-1045-0, 2012a.

Tao, J., Ho, K., Chen, L., Zhu, L., Han, J., and Xu, Z.: Effect of chemical composition of $\mathrm{PM}_{2.5}$ on visibility in Guangzhou, China, 2007 spring, Particuology, 7, 68 - 75, doi:10.1016/j.partic.2008.11.002, 2009.

Tao, J., Shen, Z. X., Zhu, C. S., Yue, J. H., Cao, J. J., Liu, S. X., Zhu, L. H., and Zhang, R. J.: Seasonal variations and chemical characteristics of sub-micrometer particles $\left(\mathrm{PM}_{1}\right)$ in Guangzhou, China, Atmospheric Research, 118, 222-231, doi:10.1016/j.atmosres.2012.06.025, 2012b.

Tao, J., Zhang, L., Ho, K., Zhang, R., Lin, Z., Zhang, Z., Lin, M., Cao, J., Liu, S., and Wang, G.: Impact of $\mathrm{PM}_{2.5}$ chemical compositions on aerosol light scattering in Guangzhou - the largest megacity in South China, Atmos. Res., 135-136, 48-58, doi:10.1016/j.atmosres.2013.08.015, 2014.

Turpin, B. J. and Lim, H.: Species Contributions to $\mathrm{PM}_{2.5}$ Mass Concentrations: Revisiting Common Assumptions for Estimating Organic Mass, Aerosol Sci. Technol., 35, 602-610, doi:10.1080/02786820119445, 2001.

Wexler, A. S. and Clegg, S. L.: Atmospheric aerosol models for systems including the ions $\mathrm{H}^{+}, \mathrm{NH}_{4}^{+}, \mathrm{Na}^{+}, \mathrm{SO}_{4}^{2-}, \mathrm{NO}_{3}^{-}, \mathrm{Cl}^{-}$, $\mathrm{Br}^{-}$, and $\mathrm{H}_{2} \mathrm{O}$, J. Geophys. Res. Atmos., 107, ACH 14-1-ACH 14-14, 2002.

Wu, D., Mao, J. T., and Deng, X. J.: Black carbon aerosols and their radiative properties in the Pearl River Delta region, Sci. China Earth Sci., 52, 1152, doi:10.1007/s11430-009-0115-y, 2009.

Wu, D., Tie, X., Li, C. C., Ying, Z. M., Lau, K., Huang, J., Deng, X. J., and Bi, X. Y.: An extremely low visibility event over the Guangzhou region: A case study, Atmos, Environ,, 39, 65686577, 2005.

Xing, L., Fu, T. M., Cao, J. J., Lee, S. C., Wang, G. H., Ho, K. F., Cheng, M. C., You, C. F. and Wang, T. J.: Seasonal and spatial variability of the $\mathrm{OM} / \mathrm{OC}$ mass ratios and high regional correlation between oxalic acid and zinc in Chinese urban organic aerosols, Atmos, Chem, Phys,, 13, 4307-4318, doi:10.5194/acp13-4307-2013, 2013.

Xu, J., Bergin, M. H., Yu, X., Liu, G., Zhao, J., Carrico, C. M., and Baumann, K.: Measurement of aerosol chemical, physical and radiative properties in the Yangtze delta region of China, Atmos. Environ., 36, 161-173, doi:10.1016/S1352-2310(01)00455-1, 2002.

Zhang, L., Vet, R., Wiebe, A., Mihele, C., Sukloff, B., Chan, E., Moran, M. D., and Iqbal, S.: Characterization of the sizesegregated water-soluble inorganic ions at eight Canadian rural sites, Atmos. Chem. Phys., 8, 7133-7151, doi:10.5194/acp-87133-2008, 2008a.

Zhang, Y. H., Hu, M., Zhong, L. J., Wiedensohler, A., Liu, S. C., Andreae, M. O., Wang, W., and Fan, S. J.: Regional Integrated Experiments on Air Quality over Pearl River Delta 2004 
(PRIDE-PRD2004): Overview, Atmos. Environ., 42, 6157-6173, doi:10.1016/j.atmosenv.2008.03.025, 2008b.

Zhang, Z., Engling, G., Chan, C., Yang, Y., Lin, M., Shi, S., He, J., Li, Y. and Wang, X.: Determination of isoprenederived secondary organic aerosol tracers (2-methyltetrols) by HPAEC-PAD: Results from size-resolved aerosols in a tropical rainforest, Atmos. Environ., 70, 468-476, doi:10.1016/j.atmosenv.2013.01.020, 2013.

Zieger, P., Fierz-Schmidhauser, R., Weingartner, E., and Baltensperger, U.: Effects of relative humidity on aerosol light scattering: results from different European sites, Atmos. Chem. Phys., 13, 10609-10631, doi:10.5194/acp-13-10609-2013, 2013.
Zieger, P., Weingartner, E., Henzing, J., Moerman, M., de Leeuw, G., Mikkil A, J., Ehn, M., Pet Aj A, T., Cl Emer, K., van Roozendael, M., Yilmaz, S., Frie Ss, U., Irie, H., Wagner, T., Shaiganfar, R., Beirle, S., Apituley, A., Wilson, K., and Baltensperger, U.: Comparison of ambient aerosol extinction coefficients obtained from in-situ, MAX-DOAS and LIDAR measurements at Cabauw, Atmos. Chem. Phys., 11, 2603-2624, doi:10.5194/acp11-2603-2011, 2011. 